Edição especial - Sociedade e ambiente no Semiárido: controvérsias e abordagens

Vol. 55, p. 186-206, dez. 2020. DOI: 10.5380/dma.v55i0.73780. e-ISSN 2176-9109

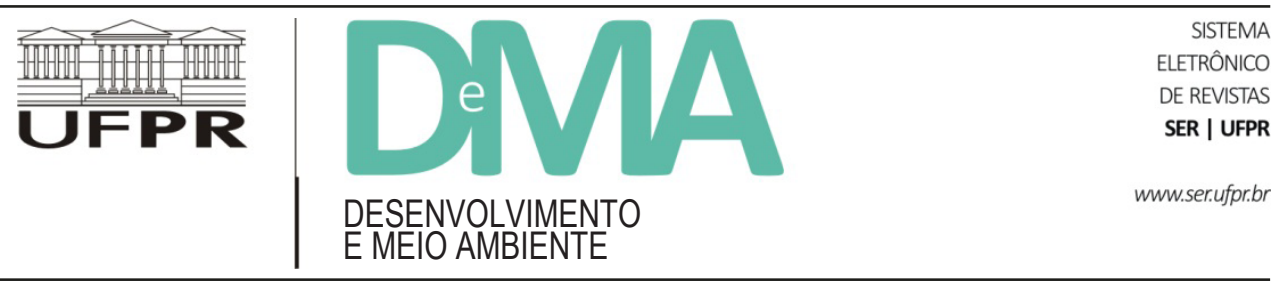

\title{
Grandes projetos, pequenas escolhas: notas sobre a desmobilização em contextos camponeses no semiárido potiguar
}

\section{Big projects, small choices: notes about demobilization in farmer contexts in the semi-arid region of the State of Rio Grande do Norte (RN)}

\author{
Melquisedeque de Oliveira FERNANDES ${ }^{1 *}$, Irene Alves de PAIVA ${ }^{2}$ \\ ${ }^{1}$ Departamento de Ciências Humanas, Universidade Federal Rural do Semiárido (UFERSA), Mossoró, RN, Brasil. \\ ${ }^{2}$ Departamento de Ciências Sociais, Universidade Federal do Rio Grande do Norte (UFRN), Natal, RN, Brasil. \\ *E-mail de contato: melquisedeque.fernande@ufersa.edu.br
}

Artigo recebido em 15 de maio de 2020, versão final aceita em 30 de outubro de 2020, publicado em 18 de dezembro de 2020.

RESUMO: Mediante a retórica do desenvolvimento, se instalam no semiárido nordestino grandes projetos que provocam profundas alterações e reordenamentos no sentido de vida compartilhado por populações locais. Este artigo busca compreender a questão da desmobilização enquanto um fenômeno produzido no contexto de dois conflitos socioambientais no RN: o primeiro é referente à chegada da revolução verde, cujo marco é a construção da barragem Armando Ribeiro Gonçalves, até hoje a maior do estado; e o segundo é relativo ao caso contemporâneo de instalação de parques de energia eólica na chamada Costa Branca, litoral norte. O cenário desses conflitos está inscrito na região oeste do estado, que concentra as principais atividades da economia primária e está altamente integrada ao mercado de commodities. Os dados trabalhados neste estudo são referentes à percepção dos estudantes do curso de Licenciatura Interdisciplinar em Educação do Campo da Universidade Federal Rural do Semiárido (Ledoc/Ufersa) que, sendo oriundos das comunidades rurais diretamente impactadas por esses projetos, estimam perdas, inconvenientes e constrangimentos mediante considerações pouco recorrentes nos estudos sobre o tema.

Palavras-chave: conflitos socioambientais; energia eólica; barragismo; perímetros irrigados; mobilização. 
ABSTRACT: Through the rhetoric of development, large projects have been installed in the semi-arid region of Northeast Brazil, which cause deep changes and rearrangements in the sense of life shared by local populations. This article aims to understand the demobilization issue as a phenomenon produced in the context of two socioenvironmental conflicts in the State of RN: the first one refers to the arrival of the green revolution, whose landmark is the construction of Armando Ribeiro Gonçalves dam, the largest dam of the state; the second one involves the contemporary case of installation of wind power parks in the area known as Costa Branca, RN's north coast. The scenario of those conflicts is located in the western region of the State, which concentrates the main activities of primary economy and is highly integrated to the commodities market. The data analyzed in this study refer to the perception of students of the Interdisciplinary Degree Course in Rural Education at the Federal University of the Semi-Arid Region (Ledoc/Ufersa), who are native from the rural communities directly impacted by these projects are able to estimate their losses, inconveniences and constraints through little considerations in studies on the subject.

Keywords: socio-environment conflicts; wind power; dam works; irrigation perimeters; mobilization.

\section{Introdução}

Este artigo se dedica a compreender as experiências de desmobilização das ações coletivas em contextos dos conflitos socioambientais gerados pela presença de grandes projetos ${ }^{1}$ na região oeste do Estado do Rio Grande do Norte. Nossa análise se inscreve numa perspectiva que observa e interpreta as experiências sob um ponto de vista que considera "as dimensões da afetividade e da sensibilidade, da memória, da imaginação e do projeto" (Cefaï, 2009 , p. 26) dos sujeitos que vivem nos territórios impactados.

O foco de investigação recai sobre as ações cotidianas e as narrativas dos sujeitos locais a respeito das mudanças que eles julgam constrangedoras ou indesejáveis em seus modos de vida. Situamos dois cenários de conflitos socioambientais nos quais empreendemos nossa análise: a construção da bar- ragem Armando Ribeiro Gonçalves, que no final da década de 1970 representou o marco da chegada da revolução verde no estado, e a instalação de parques de energia eólica na região da Costa Branca, no litoral norte potiguar.

Esses cenários nos servirão de recurso heurístico a partir dos quais serão identificados "interesses e reivindicações em torno dos recursos naturais e do território" mediante uma análise dos sujeitos sociais que leve em consideração "suas distintas cotas de poder". Trata-se, portanto, de um "mapeamento das interações políticas" mediante o qual busca-se atribuir aos diferentes grupos suas respectivas cotas de poder formal e informal (Litlle, 2006, p. 92-93).

Nesse sentido, os dois projetos estão situados enquanto estruturas que têm impactado a vida das populações locais, que percebem a si mesmas como alijadas das capacidades políticas de oferecer uma resposta comum contra as ações de agentes públicos

\footnotetext{
${ }^{1}$ Compreendemos os grandes projetos como empreendimentos de infraestrutura com alto valor orçamentário, acompanhados de grandes impactos sociais, ambientais e econômicos. Também possuem a característica de serem bastante controversos em termos de sua relação custo-benefício, quando colocados em perspectiva os orçamentos e resultados superdimensionados, frente aos subestimados impactos e danos a longo prazo (Flyvbjerg et al., 2003).
} 
e agentes econômicos. A região oeste do Estado do Rio Grande do Norte concentra uma robusta economia primária, com destaque para a fruticultura irrigada $^{2} \mathrm{e}$ a produção de energia eólica ${ }^{3}$. Em ambos os contextos, os conflitos socioambientais apresentam um aspecto silencioso, que será estudado aqui como produção da desmobilização mediante estruturas sociais e ações de atores implicados nas disputas pelo uso e pela ocupação do espaço, definição de sentido para vida nas comunidades rurais, atribuição de riscos e distribuição de danos.

É comum que os estudos sobre conflitos e mobilizações envolvendo a construção de represas (Scherer-Warren \& Reis, 1986; Sigaud, 1986; Oliveira \& Rothman, 2008; Araújo, 2019) se dediquem a compreender as ações coletivas, ressaltando as estratégias de mobilização dos atores e os recursos utilizados em protestos e confrontos políticos (Tarrow, 2009). Suas ênfases geralmente recaem sobre as ações de resistência, contestação e reivindicação organizadas pelos atores em disputa. Já os estudos que definem a medida dos impactos sociais relativos à instalação de parques de energia eólica privilegiam instrumentos de mensuração meramente técnica, que raramente levam em consideração a experiência subjetiva das populações locais (Saidur et al., 2011; Pinto et al., 2017).

Corroboramos a concepção de que a ação coletiva

é vertebrada pelos agenciamentos, comportando pessoas e objetos, ferramentas e falas, rituais e sím- bolos; ela é armada por rotinas e hábitos, ordenada por divisões do trabalho, repartições de poder e distribuições do saber, fixadas em ambientes de objetos, dispositivos sociotécnicos e circuitos operacionais (Cefaï, 2009, p. 22).

Nas experiências aqui analisadas, marcadas por certa "desmobilização", encontramos vários desses elementos nas narrativas e no repertório que justificam as práticas e sentimentos dos nossos informantes.

Metodologicamente nos alinhamos com a noção de "ecologia política como etnografia" de Paul Little (2003; 2006), mediante a qual a análise de contextos de conflitos socioambientais deve levar em consideração tanto o mundo biofísico quanto o mundo social, num esforço de reconciliação epistemológica entre as áreas, mediante um tratamento complexo e transdisciplinar dos dados. Essa abordagem leva em consideração a capacidade de relativa agência da natureza em suas diferentes escalas (organismo, população, habitat, ecossistema, bioma, continente e planeta), bem como as relações que estabelecem com o mundo social, produzindo fenômenos tais como migrações, catástrofes e mudanças bruscas da paisagem. Essa abordagem metodológica permite acionar outras perspectivas teórico-metodológicas para interpretar as experiências, descrevendo as interações, seus contextos e as capacidades reflexivas dos sujeitos (Giddens, 2003).

Os dados aqui analisados compreendem as falas, as narrativas e os depoimentos obtidos com os

\footnotetext{
${ }^{2} \mathrm{O}$ estado foi integrado ao mercado internacional de frutas frescas depois da construção de dois perímetros irrigados: Perímetro Irrigado Baixo-Açu e Perímetro Irrigado Santa Cruz do Apodi. O primeiro é o que está em questão neste estudo.

${ }^{3}$ De acordo com dados de novembro de 2018 da Associação Brasileira de Energia Eólica (ABEEólica), o Brasil possui 568 parques de produção de energia eólica, dentre os quais 472 estão localizados na região Nordeste e 146 estão instalados apenas no RN.
} 
estudantes do curso de Licenciatura Interdisciplinar em Educação do Campo da Universidade Federal Rural do Semiárido (Ledoc/Ufersa). Trata-se de uma licenciatura exclusiva para moradores de comunidades rurais do semiárido, dispondo de um currículo de formação de professores que privilegia as questões do campo e um perfil de egresso com capacidade de se articular localmente na busca de soluções para problemas comuns. Enquanto professor da Ledoc, no segundo semestre do ano de 2018 realizamos um debate envolvendo os estudantes e extensionistas do Centro de Referência em Direitos Humanos do Semiárido da Ufersa-CRDH/Ufersa, com a temática dos conflitos socioambientais no estado. Sob orientação do docente, os estudantes foram solicitados a levantarem em suas comunidades a percepção de moradores sobre conflitos socioambientais presumidamente existentes. Para este estudo, selecionamos as narrativas recolhidas por dois grupos de alunos: um composto por três estudantes, moradores da região atingida pela construção da barragem Armando Ribeiro Gonçalves, e outro grupo de sete alunos moradores da região da Costa Branca, especificamente os municípios de Areia Branca e Serra do Mel. Considere-se, portanto, que os dados levantados por esses estudantes, bem como suas narrativas, passam pelo filtro de uma formação que, segundo a concepção de Giddens (2003), desenvolve sua capacidade de agência.

A natureza subjetiva dos dados aqui analisados é proveniente de observação que considera a complexidade e a intensidade da participação dos sujeitos nas situações de pressão ecológica, de determinação econômica, da lógica social e da violência simbólica (Cefaï, 2010). Desse modo, incluímos também em nossa análise situações ocorridas ao longo de dois anos de contato com esses estudantes e suas descrições sobre seu cotidiano, bem como nossa experiência de pesquisa, desde 2007, sobre as dinâmicas de organizações políticas dos assentamentos de reforma agrária no estado, sob uma perspectiva que privilegia o conflito e a formação de rivalidades internas.

Assim, descrevemos a realidade social do território do semiárido a partir de narrativas, gestos e repertórios dos alunos e alunas da educação do campo que exprimem a forma como estes explicam, classificam e codificam seu mundo social. A forma desagradável e inconformada como descrevem as alterações na paisagem e no cotidiano, bem como a ênfase que escolhem dar aos relatos recolhidos, são analisadas aqui não como agentes alienados e manipulados ou como atores estratégicos, mas em suas interações realçamos a maneira como se sentem ante a presença de grandes projetos. Partimos do pressuposto que a descrição da afetividade, das sensibilidades e das imaginações que se apresentam nos espaços públicos compõem o que classificamos como realidade social que, segundo Bourdieu,

\begin{abstract}
engloba todas as lutas, individuais e coletivas, que pretendem conservar ou transformar a realidade, e em particular aquelas que têm como desafio a imposição da definição legítima da realidade e cuja eficácia propriamente simbólica pode contribuir à conservação ou à subversão da ordem estabelecida (Bourdieu, 2009, p. 237).
\end{abstract}

De certo modo, ao lidarmos com as múltiplas identidades desses sujeitos (sitiantes, quilombolas, pescadores, assentados de reforma agrária), estamos diante da representação de valores e modos de vida associados ao "primitivo". Jesse Souza (2014), em seu texto sobre o "racismo científico", afirma que desde Platão a moral ocidental foi assim cindida: 
de um lado, a "dominação dos afetos" que hoje caracteriza o espírito científico; de outro, as formas de conhecimento identificadas como primitivas, particularistas e motivadas por uma reflexão não distanciada dos afetos. Assim, assumimos neste texto uma escrita de enquadramento mais sensível, tingida de uma tonalidade metafórica, a fim de maximizar os sentidos atribuídos pelos sujeitos em suas falas e ao mesmo tempo superar o tratamento dos sentimentos como um não-dado científico. As percepções de "impotência", de "não saber" ou "não ter mais o que fazer", a "sensação de abandono" ou de "ter sido enganado", são chaves interpretativas importantes para compreendermos o fenômeno da desmobilização em contextos de conflito socioambiental.

É importante ressaltar que esta não é uma análise específica sobre conflitos socioambientais, nem tampouco uma avaliação sobre a implementação de grandes projetos no semiárido, com desdobramento sobre os méritos de seus resultados em termos de geração de renda ou incremento das economias locais. O que queremos aqui é compreender certo perfil de ação coletiva, caracterizada pela minimização do elemento mobilização. Cada uma das duas seções a seguir foi escrita mediante um esforço de tradução da forma como os sujeitos experimentam e narram o avanço do capitalismo agrário em seus territórios, com ênfase nas sensações de danos, perdas, inconvenientes e a percepção de impotência frente à ação do poder público e dos agentes econômicos.

\section{A lápide}

Suspensa sobre um imenso espelho d'água encontra-se uma cruz, aparada por uma torre que costumava ser da Igreja de Nossa Senhora da Conceição, na extinta cidade de São Rafael, localizada no semiárido do RN. Dá-se o nome de antiga porque toda a cidade foi encoberta pelas águas daquele que, até hoje, é o maior reservatório de água do estado. A construção da barragem Armando Ribeiro Gonçalves, no início da década de 1980, foi resultado dos planos do governo civil-militar de criar perímetros irrigados no Nordeste, mediante orçamento da Superintendência do Desenvolvimento do Nordeste - SUDENE - e execução do Departamento Nacional de Obras Contra as Secas - DNOCS, a fim de integrar a produção dessas áreas com o crescimento da demanda internacional por frutas frescas.

A cidade a ser inundada contava com mais de sete mil habitantes, em sua grande maioria camponeses. A fração urbana da população foi reacomodada em outra cidade, a nova São Rafael, enquanto a maior parte, composta pelos moradores das áreas de várzea do rio Piranhas-Açu, teve um destino mais ou menos pueril. Como se deu a desapropriação de tamanho número de pessoas com o mínimo de ruído social?

Desde que a cidade foi submersa, a cruz da antiga Igreja permaneceu ali, hasteada, como se fosse a lápide de um túmulo. Sob ela padecia uma paisagem natural e social inteira, que incluía o vale fértil do rio, habitat de diversas espécies animais e vegetais, com destaque para as extensas e produtivas matas de carnaubais, e uma pequena cidade em que várias gerações fixaram um sentido de vida coletivamente compartilhado. No final de 2018, a cruz também foi deitar-se no fundo escuro da barragem junto das outras coisas que lá se deterioram até serem reduzidas a lama.

Aqui estamos diante do que Zhouri \& Laschefski (2010, p. 18) chamam de conflitos so- 
cioambientais distributivos: "São conflitos que, manifestadamente, indicam graves desigualdades sociais em torno do acesso e da utilização de recursos naturais". Guardadas as proporções do estado, também estamos lidando com um tipo clássico de grande projeto, que é o represamento de um rio, por iniciativa do Estado, para fins de abastecimento da matriz energética (hidrelétricas) ou para criação de perímetros irrigados, com forte impacto sobre o reordenamento do uso da terra entre grupos camponeses e a destruição de extensas paisagens vivas.

Conforme chamou atenção Lygia Sigaud (1986), em seu conhecido estudo comparativo sobre os projetos de construção das barragens de Sobradinho/BA e Machadinho/RS, no primeiro caso o desempenho do governo autoritário da década de 1970 na condução das ações da obra foi de providencial importância para que a população fosse compulsoriamente deslocada e suas reações, inibidas. Contudo, conforme adverte a autora, não dá para generalizar a noção de "impacto" a partir dos resultados das ações do Estado, mas mediante um resultado - provisório - de uma estruturação das relações de força entre os atores envolvidos no evento.

No caso aqui analisado, as pressões, tomadas de posições e assimetrias de poder somente começam a se definir melhor a partir do ano de 1977, na oportunidade em que os grandes proprietários do vale do Açu começam a se articular em resposta à queda no valor de seus imóveis, em razão de seu bloqueio cartorial para venda e da suspensão do crédito agrícola para os mesmos. Essas medidas foram tomadas em consequência de um decreto assinado em 1975, pelo general Ernesto Geisel, desapropriando uma área que correspondia à fração de 3\% do território potiguar (Santos, 2019).
Em decorrência dessas medidas, o valor dos imóveis caiu rapidamente e os empresários logo se articularam com o poder público local em reação às suas perdas anunciadas:

O I Simpósio de Desenvolvimento Social do Vale do Açu, ocorrido em janeiro de 1977, foi organizado pela Secretaria Estadual de Trabalho e Bem-Estar Social. Vários temas foram abordados por técnicos e representantes das secretarias estaduais, com ênfase nas questões específicas do PBA [Plano Básico Ambiental], consideradas graves e preocupantes para os empresários e proprietários do Vale (Santos, 2019, p. 03).

Dessa reunião criou-se uma comissão especialmente designada para lidar com a questão da barragem, que incluía o prefeito, o padre, o secretário de Agricultura, o secretário de Trabalho e um político e latifundiário local - não está registrada a presença de nenhum representante de movimento social ou sindical.

Antes desses eventos, as informações circulavam de forma mais ou menos especulativa, segundo o enquadramento da imprensa local. Uma de nossas informantes, nativa do município de São Rafael, descreve que entre a população mais ampla a sensação era de muita confusão, em razão da polêmica que rapidamente conduziu para a polarização das opiniões.

Os sindicatos dos trabalhadores rurais, que rapidamente se articularam sob a liderança do STR de Açu, só passaram a participar sistematicamente das negociações oficiais a partir de 1979, quando a decisão de regulamentar 91 mil hectares para a construção da barragem, por parte do DNOCS, tornou-se um fato quase irreversível. Diante disso, os grandes proprietários das terras a serem inundadas 
construíram uma aliança com os setores populares organizados. Em resposta, os agentes interessados na construção da barragem lançam mão de um expediente comum de propaganda pública:

Em junho de 1979, na época em que se inicia a construção da barragem, foi criado, na cidade de Assú, o jornal $O$ Vale, cujo editorial anunciava a preocupação que o governo tinha para com a região [...] $O$ Vale mostrava que a situação era urgente e não devia se perder tempo com debates (Souza, 2010a, p. 61).

Nesse momento, foi deflagrada a disputa entre as diferentes narrativas e possibilidades de descrever subjetivamente o conflito, o que Teixeira (2018) trata a partir da noção de "subjetivação política" dos fatos: a forma subjetiva como diferentes sujeitos descrevem uns aos outros e a si mesmos, mobilizando um conjunto de categorias, discursos e representações que tenta circunscrever e classificar medidas de reparação e compensação.

Nesse sentido, o projeto de construção da barragem, incluindo aí sua interface de diálogo com a população a ser impactada, é marcadamente redutivo e generalista em relação ao reconhecimento da complexidade dos modos de vida no local. Zhouri \& Laschefski (2010, p. 18), em referência ao pensamento de Lefebvre (2013), afirmam que "qualquer planejamento, concepção ou representação do espaço é uma redução da realidade, conforme a percepção dos seus idealizadores. Os conflitos se materializam quando essas percepções de espaço são transferidas para o espaço vivido".
Nesse contexto de disputas, a propaganda governamental se confunde com os textos dos jornais alinhados com o projeto da barragem, no geral, mobilizando palavras como "combate à seca", "progresso" e "interesse nacional" . Em contraste, reduzia o contexto social do lugar à imagem estereotipada da pobreza nordestina. $\mathrm{Na}$ atualidade dos fatos, Traíra, um famoso poeta da região, chegou a compor um verso - não se sabe se a convite ou por contra própria - em que dizia: "Porque quiseram entravar, tão grande empreendimento, aqui só há sofrimento, nudez, desemprego e fome" (Souza, 2010a, p. 62).

Esse discurso, que emoldura a população local em sua dimensão de escassez material, tem o efeito de poder refletir na própria população o sentimento de pequenez dentro da distribuição das capacidades de ação. Por concentrar os meios legais de arbitrar sobre os conflitos, pela disposição de certos recursos técnicos e pela capacidade privilegiada de produzir uma "subjetivação política" dos fatos, o Estado e seus apoiadores, na forma de uma fração da elite local, conseguiram compor uma coalizão que disputou - com sucesso - a agenda das reivindicações, introduzindo como ponto principal a questão das indenizações.

A forma autoritária como era conduzido o projeto gerava indignação generalizada e a situação era caracterizada em termos de oposição DNOCS versus sociedade. Nestas condições, a aliança entre os diversos segmentos sociais havia sido selada em nome do combate ao PBA - máxime nos aspectos considerados injustos ou desnecessários -, porém,

\footnotetext{
${ }^{4}$ É interessante notar como as populações camponesas estão sempre reféns do contraditório "interesse nacional": ora são valorizadas por dar conta da demanda interna de alimentos, ora desvalorizadas em seu modo de vida quando diante de sua expropriação para implementação de algum grande projeto.
} 
o que os grandes proprietários reivindicavam em regime de urgência era a liberação das terras situadas à jusante da barragem, pois, com a construção da obra, haveria oferta hídrica para o agronegócio, valorizando sobremaneira essas propriedades (Santos, 2019, p. 12).

Em resumo, o conflito concentrou dois polos de oposição que coincidiam com a representação cartográfica do projeto: os proprietários das terras que seriam imediatamente desapropriadas à montante da barragem se colocaram em oposição ao DNOCS, questionando a depreciação do preço no mercado de terra em razão do já mencionado bloqueio cartorial e suspensão dos créditos públicos. Atraíram para sua órbita os setores populares organizados na figura dos Sindicatos de Trabalhadores Rurais, incluindo também a Igreja Católica, que na oportunidade lhes prestava apoio. Com o avanço das obras, eles compuseram um bloco mais ou menos homogêneo, que confundia os interesses da população impactada no campo e na cidade com a mera questão do valor das indenizações. Sobre estes últimos, é importante situar que nas extensas matas de carnaubais viviam muitas famílias de não proprietários, que migraram para o vale depois da mecanização das salinas, por volta dos anos 1940, atraídos pela atividade de extração da cera de carnaúba, na época altamente demandada no mercado internacional ${ }^{5}$ (Silva \& Silva, 2006).

O destino, portanto, desses e outros não proprietários de terras ficou projetado para as duas etapas subsequentes do projeto: a construção do perímetro irrigado do Baixo-Açu estava prevista em três etapas, sendo a construção da barragem apenas a primeira delas. A segunda implicaria o assentamento de famílias em torno da criação de um polo pesqueiro, e a terceira projetava a criação de um perímetro público irrigado de 22 mil hectares, destinados prioritariamente para o assentamento de 3.500 colonos. Efetivamente, todas as três etapas se resolveram na primeira: a barragem foi construída em regime emergencial e as famílias a serem reassentadas foram submetidas a um tempo de espera muito longo, que culminaria, justamente, com o não cumprimento das duas etapas seguintes.

Na medida em que perceberam que as etapas posteriores do projeto seriam abandonadas, as multinacionais do ramo da fruticultura irrigada para exportação passaram a expressar seu interesse pela aquisição das terras que formariam o perímetro irrigado. Com a liberação para a venda, os proprietários que apoiaram o projeto tiveram sua contrapartida atendida pelo vertiginoso crescimento do preço no mercado das terras localizadas à jusante da barragem:

\begin{abstract}
Os grandes proprietários rurais haviam conseguido êxito na empreitada pela liberação destas terras, embora a imprensa não noticiasse o fato como conquista dos empresários rurais, mas como uma questão de ordem jurídica e outra de natureza econômica. Para a primeira, o DNOCS explicava que o Decreto 76.046 de 27 de julho de 1975 havia caducado e a área destinada à irrigação não seria mais desapropriada. Quanto a segunda, apontava a ausência de recursos, pois somente a área da bacia hidráulica tinha orçamento para indenização (Santos, 2019, p. 13).
\end{abstract}

Enquanto as empresas se instalavam, abastecidas de subsídios e incentivos por parte dos go-

\footnotetext{
${ }^{5}$ Pela sua ampla aplicação na indústria bélica, o preço da cera de carnaúba subia conforme se agravavam os conflitos da II Guerra Mundial.
} 
vernos, as famílias aguardavam em assentamentos improvisados, formados por casas de taipa, sem terra apropriada para a agricultura, sem saneamento e, ironicamente, sem água. A instalação do Projeto Baixo-Açu, originalmente apresentado como solução para os problemas da seca na região, foi certamente o evento que marcou a chegada da revolução verde no estado do Rio Grande do Norte (Albano \& Sá, 2008).

Foi assim que o poder público, representado pelo DNOCS, conseguiu promover o reordenamento do uso do fértil território do Vale do Açu em proveito da revolução verde e das multinacionais que dela dependem, e em flagrante prejuízo dos grupos camponeses. Por sua vez, os grandes proprietários de terra e setores da política local se dividiram entre os que viram nisso uma oportunidade e os que tentaram amortizar seus prejuízos.

No fim, ocorreu o que se chama friamente na linguagem da economia política de "liberação da força de trabalho", que deveria ser absorvida pelas monoculturas de frutas recém-instaladas. Mas não foi o que ocorreu. Altamente mecanizadas, as multinacionais absorveram mão de obra qualificada de outras regiões, oferecendo para a população do entorno poucos postos de trabalho sazonais e segundo relação de trabalho de tipo muito flexível (Silva \& Silva, 2006).

Outra de nossas informantes investidas na tarefa de levantar os dados deste conflito descreveu o evento e suas consequências a partir de perdas não contabilizadas no discurso oficial e pouco exploradas em relação ao conjunto da produção acadêmica sobre o contexto. Ela narrou que, no cenário urbano, os moradores sofreram com a perda das representações de "lugar": em razão da construção da barragem, as coisas que, na antiga cidade, estavam em seu devido lugar, com a construção da nova pareciam não estar mais, segundo descrevem os moradores. As novas ruas não têm as mesmas dimensões, os vizinhos não são os mesmos, o tamanho e a arquitetura das casas também não respeitam os padrões anteriores. Para essas pessoas, entram na contabilidade as perdas referentes ao capital social, a paisagem com a qual estavam familiarizadas e certo sentido de vida socialmente compartilhado, que persiste mediante a mobilização das memórias da cidade.

No que diz respeito às indenizações, uma terceira informante defende que o valor pago às famílias foi desprezível, se comparado com o estimado por elas. Já os impactos, em sua avaliação, foram inúmeros. Uma ampla paisagem de mata nativa se perdeu, e junto dela a biodiversidade. Outro ponto mencionado foi a inundação das áreas de várzeas muito férteis: antes da barragem havia no local uma agricultura familiar, em seu ponto de vista, bem desenvolvida, com até duas colheitas ao ano. Para ela o município contava com uma vida econômica bastante ativa, baseada na agricultura, pecuária, artesanato de palha de carnaúba, extração de scheelita e outros minérios. A feira da antiga São Rafael tinha uma grande movimentação comercial, sendo a maior e a mais procurada da região. Afirma ela que a parte inundada correspondia às áreas mais férteis do estado. Posto isso, conclui sua narrativa sobre o desfecho dos fatos com a pergunta: "Tudo isso para quem?"

Com o projeto de construção da barragem Armando Ribeiro Gonçalves, o território do Vale do Açu foi integrado à atualidade das cadeias globais de produção de commodities. Hoje o Brasil é um dos maiores produtores mundiais de frutas frescas para exportação, sendo o semiárido do Rio Grande 
do Norte uma região estratégica pela presença do perímetro irrigado Baixo-Açu e o recém-instalado Perímetro de Santa Cruz do Apodi 6 .

No ano de 2019 o Brasil bateu o recorde histórico de um bilhão de dólares em exportações de frutas? ${ }^{7}$ John Wilkinson (2002) afirma que o crescimento recente no interesse de mercados como o europeu e estadunidense pelo consumo de frutas tropicais se deu em razão de um acúmulo de crítica, por parte dos especialistas em saúde nesses países, sobre a indústria alimentar e seus alimentos ultraprocessados. Em razão dessa crítica, o estímulo ao consumo de alimentos frescos cria uma reconsideração sobre os hábitos alimentares ${ }^{8}$ das populações nesses epicentros da economia capitalista, defendendo um valor "natural" do alimento, com ênfase nas suas propriedades funcionais ao organismo.

Em resposta a esse incremento de demanda, os polos irrigados se configuram como um reordenamento do uso da terra e das relações sociais ali presentes em proveito de um controle dos territórios cada vez mais centralizado por grupos nacionais e estrangeiros que operam no mercado global. Segundo a tese de Vandana Shiva, as formas de vida alternativas ao avanço do capitalismo agrário precisam ser deterioradas de tal modo que só reste o monocultivo como solução à "falta de alternativas". O discurso do combate à pobreza e à fome é mobilizado para gerar mais pobreza e fome. As monoculturas são, ao mesmo tempo, uma natureza empobrecida - em face dos ecossistemas complexos e produtivos - e empobrecedora - pela expropriação das condições de reprodução material e social dos sujeitos investidos na manutenção desses ecossistemas. No centro da produção da desmobilização estão os processos de expropriação: "as monoculturas disseminam-se não por aumentarem a produção, mas por aumentarem o controle" (Shiva, 2003, p. 18).

Essa tese do reordenamento do uso do território para fins de deslocamento do seu controle se confirma no caso em questão. "No projeto Baixo-Açu (RN), são 197 irrigantes: 156 pequenos produtores $(25,73 \%)$ e 25 empresas $(7,88 \%)$. Os pequenos irrigantes concentram $25,73 \%$ da área total contra $70,15 \%$ da área destinada às empresas" (Pontes et al., 2013, p. 3216).

$\mathrm{Na}$ fala dos nossos informantes, é comum a menção à empresa Agrícola Famosa, uma das maiores produtoras mundiais de melão, que atua na região em parceria com a gigante alemã Bayer. São comuns também aqueles estudantes que trabalharam nas fazendas da empresa suíça Syngenta, localizadas na fronteira do Ceará com o Rio Grande do Norte. Suas descrições confirmam o que dissemos anteriormente sobre as relações de trabalho dentro de padrões altamente flexíveis.

\footnotetext{
${ }^{6} \mathrm{O}$ segundo perímetro potiguar de agricultura irrigada Santa Cruz do Apodi foi criado no contexto das obras do Plano de Aceleração do Crescimento - PAC, mediante decreto de 10 de junho de 2011 da Presidência da República, que decretou a desapropriação de área de terra de 13.855,13 hectares, com a previsão de investimento público na ordem de R\$ 209.208.693,30 (Pontes et al., 2013).

${ }^{7}$ Globo Rural. Brasil bate recorde e atinge pela primeira vez US\$ 1 bilhão em exportação de frutas. Rio de Janeiro, 2020. Disponível em: $<$ https://revistagloborural.globo.com/Noticias/Economia/noticia/2020/01/brasil-bate-recorde-e-atinge-pela-primeira-vez-us-1-bilhao-em-exportacao-de-frutas.html>. Acesso em: fev. 2020.

${ }^{8}$ Conforme identifica Sidney Mintz (2003) em seu estudo sobre o açúcar, a mudança nos hábitos alimentares na Europa criou as condições para que, nos trópicos, se instalassem as monoculturas orientadas para exportação. Em momentos e espaços diferentes, todo o chamado Novo Mundo teve o uso da terra reordenando para abastecer a crescente demanda dos europeus por açúcar, tabaco, café, cacau e outras gêneros tropicais.
} 
Os grandes fruticultores, com alto capital para investimento, optam pela mecanização e automação, bem como por serviços terceirizados. As relações de trabalho são de três ordens: uma fração pequena de seus trabalhadores, denominados de "qualificados", é contratada em caráter assalariado e permanente, para atuar em áreas como pesquisa e controle da produção; uma fração maior compreende os trabalhadores de baixa remuneração, mas assalariados, permanentes e temporários, que compõe "equipes ambulantes" que atuam nas "práticas delicadas" em cada unidade de produção (polinização, podas, colheita, seleção e classificação); mas o massivo dos trabalhadores é temporário e assim denominado de não qualificado, completamente fora das garantias do mercado formal de empregos (Silva \& Silva, 2006).

Mas não são todas as empresas que precisam adquirir terras para produzir na região. Algumas agroexportadoras produzem mediante parcerias em assentamentos de reforma agrária. São empresas que atuam amplamente no $\mathrm{RN}$, firmando parcerias com famílias assentadas, onde instalam projetos produtivos oferecendo suporte técnico e garantia de mercado para os produtos, enquanto as famílias parceiras acessam seus créditos para investir na produção e oferecem, como contrapartida, sua força de trabalho, seus lotes de terra e benfeitorias coletivas, como poços artesianos e outros mananciais de água.

Em nossas pesquisas anteriores ${ }^{9}$, verificamos que as famílias que em algum momento tiveram que abrir mão de sua agricultura de base ecológica viram sua força de trabalho automaticamente anexada ao mercado internacional de frutas frescas para exportação e, por essa razão, ficaram vulneráveis às flutuações desse mercado, de maneira que a escala do risco a que estão submetidas vai do salário à saúde, passando pela deterioração de seu capital de base ecológica (Van Der Ploeg, 2009) e, finalmente, pelo comprometimento das reciprocidades de base comunitária (Alavi, 1976).

Até aqui tentamos responder parcialmente à pergunta que fizemos no início desta comunicação: como é possível remover uma população inteira de lugar com o mínimo de ruído social? Além da “subjetivação política" na construção desproporcional da narrativa sobre os fatos, existe também uma temporalidade característica da cena do conflito. Assim como demonstra o projeto de construção da barragem, o processo acontece em etapas. E ainda que a primeira etapa seja a única, é preciso que haja outras, pelo menos meramente projetadas como promessa.

O caso da implementação do Projeto Baixo-Açu é um exemplo de como a população afetada foi alijada das condições de mobilização antes mesmo que pudesse se reunir. As promessas se confundem com o volume de informações que circulam e que certamente ajudam a gerar controvérsias, que transitam entre o discurso oficial e os rumores meramente especulativos. Conquanto alimentam as incertezas, as promessas são estratégicas em submeter as pessoas ao tempo lento da espera. As obras da barragem ocorreram em um regime de urgência e o reassentamento das famílias em um tempo diluído no esquecimento. Quando uma de nossas informantes foi questionada dos motivos pelos quais as pessoas, na época, não haviam feito

\footnotetext{
${ }^{9}$ Cf.: Fernandes, M. de O. O conflito organizado: uma abordagem faccional da organização produtiva em assentamentos rurais do RN. Natal, Tese (Doutorado em Ciências Sociais) - UFRN, 2015.
} 
algo para impedir a construção da barragem, ela nos respondeu com uma pausa, ainda ensaiou alguma resposta, mas finalmente permaneceu em silêncio. Curioso notar como a resposta para essa pergunta é quase sempre algum tipo de silêncio, de quem não tem o que dizer, ou de quem presume que a resposta seja óbvia demais para ser pronunciada.

No que se refere às perdas em relação à paisagem viva, um relatório ${ }^{10}$ publicado em 2007 pelo governo do estado da Paraíba chegou à conclusão de que alguns dos projetos de irrigação estão invadindo a área de preservação permanente do rio. Constatou também a eutrofização ${ }^{11}$ da água da barragem.

Outro estudo (Ramalho, 2009) menciona que, na atualidade da pesquisa, restavam menos de $45 \%$ da mata de carnaubais que originalmente compunham o vale. O mesmo estudo aponta o comprometimento da maior lagoa do estado, a Lagoa de Piató, que, estando localizada à jusante da barragem, teve seu abastecimento condicionado à vazão do reservatório, de modo que atualmente encontra-se em ciclos de seca cada vez mais frequentes e longos. De acordo com matéria jornal Tribuna do Norte (2015), as 400 famílias que obtêm sua renda a partir da lagoa estão em franco processo de pauperização. Uma das entrevistadas assim descreve o fenômeno: "O rio que abastecia a lagoa perdeu a força".

\section{O jumento}

No semiárido nordestino, o jumento é um animal muito comum no imaginário popular e está associado, principalmente, a uma posição desvantajosa nas trocas simbólicas e materiais. Mas o jumento também está associado a uma forma de "ser e estar" no mundo. São numericamente abundantes e têm um baixíssimo valor de mercado. Na família dos equinos, não possuem o mesmo status dos cavalos, raramente recebem um nome próprio, muito menos são utilizados para prática de esportes. Seu valor de uso, ao contrário, é bastante alto, uma vez que é designado para diversas tarefas exaustivas, sendo muito frequente seu uso como meio de transporte e tração de carroça.

Diversos estudos de universidades do RN têm apontado para queixas comuns de segmentos camponeses em contato com os parques de energia eólica, dentre as quais destacam-se: a) a promessa de geração de emprego, que não se cumpre para além do período de instalação dos parques; b) a inflação nos preços da terra, dos alimentos e dos imóveis na sede do município; c) privação de caminhos e acessos pelos quais costumavam circular; d) o abandono, por parte dos pais, das crianças nascidas do relacionamento entre trabalhadores "das eólicas" e moradores locais, fenômeno denominado de "filhos do vento" (Improta, 2008; Rozendo et al., 2014; Costa, 2015; Cruz, 2016).

Em face dos inconvenientes vividos em seu cotidiano, nossos informantes afirmam essa mesma ordem de questões, nos oferecendo detalhes sobre como percebem suas possibilidades de ação. As comunidades em questão compreendem o Assentamento Garavelo, em Areia Branca, e as vilas localizadas na fronteira deste município com Serra

\footnotetext{
${ }^{10}$ Governo do Estado do Paraíba. Levantamento ambiental do rio Piranhas-Açu. Agência Nacional das Águas, 2017. Disponível em: <http:// www.aesa.pb.gov.br/aesa-website/wp-content/uploads/2016/11/doc_PA_08.pdf $>$. Acesso em: fev. 2020.

${ }^{11} \mathrm{Na}$ ecologia dá-se o nome de eutrofização para a concentração de matéria orgânica em um corpo d'água, deixando-o com coloração esverdeada.
} 
do $\mathrm{Mel}^{12}$. Os dados a seguir serão tratados como uma realidade comum, tanto pela reincidência das mesmas questões quanto para preservar $\mathrm{o}$ anonimato de nossos informantes, que poderiam ser facilmente identificados de posse dos dados de seu curso universitário e detalhes sobre seu local de moradia.

"Professor, se um dia você tiver um lote de terra e alguém botar lá uma torrezinha vermelha é melhor você ceder, porque uma hora você vai ter que ceder". Essa é a fala de uma de nossas informantes, moradora de uma comunidade rural na região em questão. Ao mencionar a "torre vermelha", ela se referia aos estudos de viabilidade técnica que antecedem a instalação dos parques.

Essa conclusão é deduzida a partir da experiência de seu avô, que havia arrendado suas terras para uma empresa de energia eólica, que por sua vez lhe paga uma cota proporcional, na forma de royalties, relativa à produção de cada aerogerador instalado. $\mathrm{Na}$ opinião de nossa informante, o rendimento dos royalties está aquém do projetado na época em que as famílias da comunidade de seu avô concordaram com a instalação das torres, sendo elas motivadas a arrendar suas terras para a instalação de várias torres, a fim de obter uma renda satisfatória.

Embora esse seja um detalhe importante, não era disso que ela se queixava. Ela queria chamar atenção para o sofrimento psíquico de seu avô que, dispondo da renda "das eólicas", deixou o campo e foi morar na cidade. Ele não conseguiu se adaptar à vida urbana, nem tampouco via sentido em retornar para sua comunidade rural, uma vez que muitos de seus vizinhos se ausentaram do lugar da mesma forma que ele, assinando um contrato que varia entre 30-50 anos. Pelo que ela descreve, o espaço onde seu avô vivia foi relativamente esvaziado, tanto de produção agrícola quanto das reciprocidades de vizinhança tipicamente camponesas, não obstante ocupado pelos aerogeradores.

A descrição dessa estudante coincide com o que Zhouri \& Laschefski (2010, p. 23) chamam de conflitos ambientais espaciais: "uma situação que envolve os atingidos por contaminação, ou por exposição a uma emissão ameaçadora para a qualidade de vida, que se sentem obrigados a se deslocalizar". Talvez devêssemos aqui colocar em perspectiva a palavra "obrigados". Ela se aplica ao nosso contexto, mas não mediante uma ordem explícita ou imposição vertical, mas, conforme descrevem nossos informantes, porque primeiro as pessoas abrem mão do trabalho na terra em razão da renda dos royalties, depois passam a "disputar" entre si o número de aerogeradores em seus lotes a fim de maximizar suas rendas, depois se ausentam do seu espaço para irem morar na sede do município. $\mathrm{O}$ resultado disso é um processo lento e fragmentado de desterritorialização: aos poucos deterioram-se as reciprocidades entre vizinhos e, por extensão disso, a produção também sofre, tanto pela perda do capital ecológico (Van Der Ploeg, 2009), que contribui para o equilíbrio ecossistêmico local, quanto pelo comprometimento das reciprocidades camponesas (Alavi, 1976), fundamentais para a manutenção da economia dos lotes.

O levantamento realizado pelo nosso grupo de informantes, bem como seus relatos pessoais,

\footnotetext{
${ }^{12}$ Serra do Mel foi um município criado na década de 1970 a partir de um grande projeto de colonização e reforma agrária que distribuiu terras para as famílias de trabalhadores desempregados em razão da automação dos parques salineiros da já citada região da Costa Branca. Na parte rural foram criadas várias vilas, cada uma com o nome de um estado brasileiro. A Vila Acre foi uma das primeiras a sediar os parques de energia eólica.
} 
converge no que diz respeito a uma série de constrangimentos que passaram a se acumular desde que chegaram os parques de energia eólica na região, hoje com destaque para a empresa Voltália, com sede na França. A depender do perfil econômico de sua comunidade de origem, eles narraram problemas que afetam diretamente a produção das comunidades pesqueiras, a produção agrícola dos cajueiros - que se destaca na região pela produção de mel e castanha-de-caju para exportação - e a reprodução da paisagem natural do bioma restinga, característico desta parte costeira do semiárido.

As perdas na produção agrícola são contabilizadas desde a abertura de novas estradas e o trânsito de veículos pesados para montagem do parque, que lançou sobre os pés de caju uma camada fina de partículas de poeira, que os moradores associam ao comprometimento da floração e da fecundação do cajueiro. Entre os relatos, é recorrente a informação de que agentes polinizadores importantes, como as abelhas, estão sensivelmente diminuindo desde a instalação dos parques.

Em áreas de boa viabilidade técnica, as torres são fixadas em linha, uma ao lado da outra ${ }^{13}$. No perímetro de cada torre é lançado cascalho de brita, a fim de evitar o crescimento da vegetação. Essa parte subtraída da vegetação nativa, associada ao deslocamento da massa de ar e ao ruído produzido pelo giro das pás, já é responsável, segundo nossos informantes, por um considerável desequilíbrio na rota das aves e pela redução da presença de flores, que por sua vez está associada à diminuição das abelhas como principal agente polinizador.
Um de nossos informantes levantou dados de uma comunidade pesqueira no município de Areia Branca e relata que, para os pescadores, o risco de morrer no mar também aumentou muito. Justifica ele que, enquanto as torres estão em operação, elas transmitem a vibração mecânica de rotação das hélices através do solo até o mar, fazendo com que os peixes se afastem na direção contrária da praia. Para os moradores, é flagrantemente distinguível a redução no número de peixes na costa quando os aerogeradores estão em movimento. Os pescadores que vão em busca dos peixes em alto-mar, contando com embarcações adaptadas apenas para a costa, acabam, por vezes, "não voltando mais".

É comum em todos os relatos a menção ao barulho emitido pela rotação das pás. Segundo seus depoimentos, o ruído varia de acordo com a quantidade de torres e a velocidade dos ventos. O principal fator de incômodo é o tipo de ruído, mais ou menos entrecortado pelo atrito de cada pá com a massa de ar, que é melhor percebido justamente à noite, quando o ambiente externo está mais silencioso e os ventos sopram com mais força. Talvez a ideia de que as pessoas que moram próximas às torres "ficam loucas" seja uma forma sintética de traduzir a perturbação dessa experiência.

Ainda que não seja nosso propósito aqui entrar no mérito específico dos impactos que envolvem a produção de energia eólica, é importante confrontarmos a fala dos nossos informantes com os resultados de pesquisas sobre o tema. No meio científico, o debate sobre os impactos da energia eólica é muito controverso. Um estudo (Saidur et al., 2011) reali-

\footnotetext{
${ }^{13}$ É emblemático o caso dos pescadores da praia de São Cristóvão, no município de Areia Branca, que tiveram o acesso ao mar bloqueado por uma verdadeira barreira de aerogeradores com seus perímetros cercados.
} 
zou um balanço da produção acadêmica em nível internacional (teses e dissertações, periódicos, conferências, relatórios, livros) e tentou ponderar as vantagens e desvantagens da energia eólica, chegando às seguintes conclusões. Entre os problemas, destaca-se a morte de aves, principalmente em razão de colisão com as pás dos aerogeradores em condições de baixa visibilidade, além de alterações e deslocamento de seus habitats. Também contam as alterações na paisagem visível, contabilizadas a partir da presença dos aerogeradores e dos cabos e torres de transmissão de energia. Finalmente, o problema mais crítico é a produção de ruído, que pode ser tanto mecânico - produzido pelo próprio movimento dos componentes físicos - quanto aerodinâmico - produzido pela corrente de ar em contato com as hélices. O mesmo estudo defende que todos esses problemas são desprezíveis se consideradas as outras formas de produzir energia, mas também não entrou no mérito da forma como esses problemas são percebidos pelas populações impactadas.

Outra pesquisa (Dai et al., 2015) aponta para as mesmas desvantagens, só que com diferentes ênfases. Os impactos ambientais consideram toda infraestrutura dos parques, além dos aerogeradores propriamente. Adiciona ainda os danos à vida marinha, afirmando que parques construídos muito próximos ao mar podem ter efeitos negativos sobre os peixes, em razão do ruído e do campo eletromagnético criado. Os impactos humanos também convergem para a questão do ruído, mas descrevendo outros efeitos, como dores de cabeça, irritabilidade, distúrbios de sono e perda da audição a longo prazo.
Em nível local, diversas pesquisas também têm se ocupado da temática dos impactos da energia eólica. A grande maioria leva em consideração a noção de "impacto" mediante instrumentos de mensuração objetiva dos eventos (Fernandes \& Junior, 2017; Felix, 2018; Brasileiro, 2019), mas são relativamente poucos os estudos que se ocuparam da escuta dos sujeitos.

Entre os nossos informantes, a deterioração das estradas nas comunidades é outro impacto apontado. Estima-se que a instalação de cada torre demanda mais ou menos 40 viagens de caminhões e baionetas ${ }^{14}$. Esses veículos são de grande porte e transportam os componentes pré-moldados dos aerogeradores. Esse fluxo de veículos, por si só, é tomado como fator de incômodo e descrito como "arriscado" para quem transita de motocicleta, veículo de uso muito comum. É dito que o peso dos caminhões provoca danos às estradas de maneira que se torna impraticável trafegar com veículos pequenos.

Um de nossos informantes, morador de uma comunidade no município de Areia Branca, teve sua propriedade cortada pelas linhas de transmissão de energia. Ele descreve que, em razão do abalo provocado pelo trânsito dos caminhões para construção de um parque eólico próximo, sua casa passou a apresentar rachaduras. Para além disso, a posterior presença dos cabos de alta tensão e suas torres no horizonte da paisagem é outro fator de desconforto visual.

Dentro da literatura especializada, as alterações da paisagem são um dos tópicos mais contro-

\footnotetext{
${ }^{14}$ Cf.: Siqueira, R. A energia eólica é mesmo limpa? Portal Ecodebate. Rio de Janeiro, 2014. Disponível em: <https://www.ecodebate.com. br/2014/04/03/a-energia-eolica-e-mesmo-limpa-artigo-de-ruben-siqueira/>. Acesso em: mar. 2020.
} 
versos: “A reação provocada por um parque eólico é altamente subjetiva. Muitas pessoas olham a turbina eólica como um símbolo de energia limpa e avanço tecnológico, outras reagem negativamente à nova paisagem" (Pinto et al., 2017, p. 1090). Essa dualidade representa certa forma de perceber a presença do parque como bem-vindo ou não.

Segundo os relatos coletados, os primeiros contatos das empresas de energia eólica com as comunidades em questão ocorreram da seguinte forma: as primeiras reuniões, ocorridas no ambiente de representação formal das associações de moradores, não deixam claro o caráter facultativo da instalação do parque, mas, do contrário, apresentam inicialmente todo o projeto como se já estivesse em vias de implementação, inclusive enfatizando o apoio da prefeitura local. Na mesma oportunidade em que as famílias foram convidadas a participar desse primeiro encontro, pediu-se também que as pessoas que tivessem interesse em trabalhar na construção do parque levassem seus currículos para concorrerem às vagas de emprego que seriam ofertadas depois da presença da empresa. Nesse contexto, as poucas pessoas que de pronto foram contrárias à instalação do parque apenas se retiram da reunião.

A partir desse momento, o acesso aos potenciais benefícios da empresa passa a ser distribuído, mediante uma espécie de atualização do clientelismo enquanto gramática de poder familiar, aos atores envolvidos. Nos depoimentos coletados, a atuação da empresa é recorrentemente confundida com as decisões dos órgãos de regulamentação local, de maneira que se atribui ao poder público e à empresa uma forma de atuação quase homogênea e fisiológica.

Tanto a seleção dos currículos quanto a escolha dos lotes onde serão instaladas as torres - e de onde se pode auferir tanto os royalties quanto as indenizações por desmatamento - obedecem, ao mesmo tempo, critérios de apoio eleitoral e cumplicidade com as ações da empresa. Fala-se de pessoas que eram profundamente contra a instalação das torres em sua comunidade, mas mudaram de opinião depois de terem um dos membros de sua família empregado "nas eólicas", ou depois de serem "favorecidas" com a regulamentação de torres em seus lotes, por parte do poder público local, em troca de manifesto alinhamento durante as eleições.

Dessa forma, os atores se reconhecem em suas respectivas cotas de poder: a) as famílias moradoras das comunidades são prontamente enquadradas e reduzidas a uma concepção de pobreza quase imanente, a partir da qual é possível debitar, ao mesmo tempo, apoio eleitoral e certa cumplicidade com a empresa em troca de empregos, indenizações e royalties; b) a empresa, por sua vez, faz questão de impor simbolicamente e desde o começo seu estoque de capital econômico e político; e c) e os órgãos do poder público local, responsáveis pelas regulamentações, concentram os recursos que são próprios do Estado, como, por exemplo, o documento enquanto dispositivo de poder ${ }^{15}$ (Foucault, 2014). Na medida em que os atores se movimentam na cena das disputas, cada um demonstra, na prática, a capacidade de impor seus interesses. A parte mais frágil estima que é mais factível negociar algum

\footnotetext{
${ }^{15}$ Exclusivamente responsável pela regulamentação da ocupação do espaço, o Estado concentra as funções legítimas de emitir autorizações, permitir ou não estudos de viabilidade técnica, aceitar ou contestar relatórios, licitações, laudos.
} 
tipo de alinhamento que se arriscar em confrontos diretos ou enfrentar uma disputa judicial contra a empresa e/ou o poder público.

No caso em questão, percebe-se que a gramática de poder do clientelismo se atualiza mediante as trocas de favores que caracterizam o que Palmeira \& Heredia (1995) chamaram de "política de facções"”. Desse ponto de vista, dada a estrutura profundamente assimétrica de distribuição de recompensas dentro das relações de barganha e apoio e, em paralelo, a fragmentação das negociações ${ }^{17}$, alinhar-se com o lado assim adjetivado de "poderoso" é antes de tudo o resultado de um cálculo racional.

As disposições constitutivas do habitus, que estão duravelmente inculcadas pelas condições objetivas e por uma ação pedagógica tendencialmente ajustada a essas condições, tendem a engendrar expectativas e práticas que são objetivamente compatíveis com essas condições e previamente adaptadas às suas exigências objetivas (Bourdieu, 2007, p. 85).

A "política de facções", por sua vez, empresta sua lógica para o que Achille Mbembe (2017) chama de "política da inimizade": um modus operandi de ocupação de territórios que alimenta e tira proveito dos conflitos em comunidades autóctones ${ }^{18}$. O que há de incomum entre a produção da inimizade e a produção da desmobilização são seus resultados na forma de perda de controle dos sujeitos sobre seus territórios, em razão da impossibilidade de uma resposta articulada.

Na medida em que se acumulam os riscos, na ordem do comprometimento da produção agrícola, danos à estrutura das casas e seus equipamentos de convivência com o semiárido - conforme foi registrado, a rachadura de várias cisternas do tipo calçadão -, o ruído que "não deixa ninguém dormir em paz" e os diversos acidentes de trabalho ${ }^{19}$ constroem um cenário de imprecisão com relação ao futuro da comunidade e vão acomodando as ações dos sujeitos dentro da lógica da inimizade. Nesse caso, o inimigo não representa um concorrente ou adversário, muito menos alguém odiado ou pelo qual se nutre antipatia, mas alguém que nega, mediante suas escolhas, certo modo de vida que se deseja defender (Mbembe, 2017).

Não consta nos relatos e depoimentos aqui estudados algum indicativo de que as comunidades

\footnotetext{
${ }^{16}$ Em seu estudo sobre as eleições numa cidade do interior do Pernambuco, os autores constataram que a decisão de se alinhar com os candidatos com maior potencial de vitória eleitoral se dava por uma previsão de melhores chances de acessar os serviços públicos posteriormente.

${ }^{17} \mathrm{Na}$ produção da desmobilização, é fundamental também fragmentar o conflito de modo a isolar um indivíduo do outro. No exemplo do rompimento da represa de Mariana/MG, em 2015, as famílias foram conduzidas para hotéis espalhados pela cidade e casas alugadas longe umas das outras (Zhouri et al., 2016).

${ }^{18}$ Os casos extremos são descritos por ele a partir das guerrilhas da África pós-colonial na forma de "gangs ou milícias controladas quer por mercenários, e outros empresários da violência que operam na sombra" resultando num contexto que "acentua o caráter funcional do terror e possibilita a destruição de qualquer vínculo social que não seja o da inimizade” (Mbembe, 2017, p. 60-61).

${ }^{19}$ Cf.: Santos, I. Jovem de 21 anos cai de torre eólica em que trabalhava e morre no RN. Portal G1 RN, 2020. Disponível em: <https:/g1.globo. com/rn/rio-grande-do-norte/noticia/2020/06/20/jovem-de-21-anos-cai-de-torre-eolica-em-que-trabalhava-e-morre-no-rn.ghtml1>. Acesso em: jun. 2020.

Portal G1 RN. Guindaste tomba e operador morre ao cair durante construção de parque eólico no RN. Portal G1 RN, 2020. Disponível em: $<$ https:/g1.globo.com/rn/rio-grande-do-norte/noticia/2020/02/06/guindaste-tomba-e-operador-morre-ao-cair-durante-construcao-de-parque-eolico-no-rn.ghtml>. Acesso em: jun. 2020.
} 
estejam abertamente fracionadas entre apoiadores e não apoiadores da ação dos parques de energia eólica. Isso inclusive é algo que varia conforme a temporalidade própria dos eventos. Ressaltam que no início prevalece um otimismo característico do acúmulo de promessas, criando um ambiente publicamente homogêneo de aceitação, enquanto que, na medida em que os problemas começam a ser percebidos, a contestação ou não dessas promessas inicia a definição das diferenças internas, que lançam ênfase sobre a distribuição desproporcional das perdas e ganhos. O "outro" é, portanto, produzido como adversário num contexto implícito de disputa pela definição de um sentido comum para a vida no local.

Certa vez, mais ou menos ao acaso, um de nossos estudantes nos mostrou um registro fotográfico que havia feito, cuja imagem continha, no primeiro plano, um jumento, e no segundo plano, acima dele, um aerogerador branco. Ao fundo, havia um céu que deveria ser azul, não estivesse a fotografia em preto e branco. O jumento olhava para a câmera com uma espécie de tristeza que é típica dos jumentos - ou do nosso olhar sobre eles. Pela área que ocupava em relação ao todo da imagem, nota-se que o animal representa algo importante, apesar de ser ele tão comum quanto os outros que vemos por aqui aos inúmeros apodrecendo no acostamento das estradas, depois de colidir com um veículo mais apressado que ele.

No que se refere à mensagem da foto, não seria demasiado especulativo supor que o estudante quisesse representar certa forma de ocupação do espaço: alto e indiferente estava o aerogerador, a converter o vento em energia mecânica, e de energia mecânica em energia elétrica, e de energia elétrica em dinheiro, que por sua vez será remetido para a matriz das multinacionais, talvez localizadas na França, Espanha ou na Coreia do Sul. Abaixo da torre um jumento, esse animal tão característico do semiárido.

Uma fotografia como essa pode ser tomada como uma representação topográfica das posições relativas de quem está acima e quem está abaixo, de quem está no controle e de quem perdeu o controle. As perdas em relação à autonomia sobre o espaço são um dado muito presente, não somente nesta, mas em outras pesquisas: "Dois entrevistados reclamam que, por conta da construção do PERF [Parque Eólico de Rio do Fogo], Zumbi não tem mais para onde crescer [...] a tendência estava sendo crescer em direção ao terreno onde está localizado o PERF" (Improta, 2008, p. 123).

Bourdieu (1997), ao falar sobre as implicações da noção de lugar, afirma que as posições ocupadas no espaço revelam muito sobre as relações de poder que o constituem. Estar muito próximo de aerogeradores aos quais atribui-se noites de sono incomodado e, ao mesmo tempo, estar muito longe do lugar para onde é remetido o lucro proveniente dessa ocupação do espaço, é um claro indicativo das cotas proporcionais de poder dos atores em disputa.

\section{Considerações finais}

Para compreender a questão da desmobilização nos dois contextos de conflitos socioambientais aqui estudados, é importante ter em mente o que diz Sidney Tarrow (2009) sobre o confronto político: ele é criado - e as pessoas passam a se engajar em torno dele - dada a ameaça de restrições políticas ou mudança em termos de benefícios acumulados. Para enfrentar um problema desse tipo, as pessoas 
acionam certos tipos de oportunidades, dentre elas: 1) repertórios de confronto que dizem respeito às convenções aprendidas de luta, culturalmente inscritas e comunicadas; 2) quadros interpretativos de significados compartilhados que têm potencial de modelar, dignificar e animar a ação coletiva; e 3) redes sociais onde são partilhadas identidades, de onde se retira um sentido para vida no interior do grupo e suas ligações com outros setores da sociedade.

No primeiro contexto, a forma autoritária como se deu a construção da barragem, as medidas adotadas pelo governo, que tiveram como consequência a queda no preço dos imóveis a serem indenizados, e o descaso com o próprio patrimônio afetivo e cultural da população local da antiga cidade e do vale fértil são um claro sinal das "violações políticas e ameaça de benefícios acumulados". Contudo, o processo de mobilização concentrado em torno das ações dos STRs e da Igreja Católica foi rapidamente capturado e assimilado pelos significados de luta da fração dos grandes proprietários, cujo interesse se concentrava no preço das indenizações. Finalmente, as identidades e os sentidos de vida compartilhados localmente foram desde o início rebaixados à antiga narrativa monotemática da pobreza no sertão do Nordeste.

No segundo contexto, observa-se uma atualização das ondas de uso e de ocupação do espaço pelo capitalismo no semiárido potiguar. Primeiro, nota-se um deslocamento do STR para as associações de moradores enquanto canal legítimo de representação e interlocução formal dos segmentos camponeses em estudo. Por extensão disso, observa-se certa permeabilidade para a fragmentação dos acordos mediante uma clara gramática de poder clientelista. Acredita-se que a formação dos sujeitos no âmbito da Ledoc/Ufersa os qualifica em termos de ação coletiva, para se posicionarem com potencial de "dignificar e animar a ação coletiva".

Finalmente, falar na mobilização enquanto fenômeno ausente não significa negar as formas presentes de ação coletiva. Conforme Cefaï (2009), ela se manifesta na dimensão da memória, dos símbolos e sentimentos fixados em objetos, de maneira que a antiga cruz da Igreja hasteada sobre o imenso espelho d'água da barragem Armando Ribeiro representava a própria resistência da população em lamentar a perda da cidade e marcar seu lugar no espaço da barragem. No caso da energia eólica, rumores dão conta de fechamentos de estradas justamente na região que analisamos aqui. Nesses casos, percebe-se uma clara apropriação de "repertórios de confronto" assimilados de outros contextos de conflitos; contudo, a deterioração dos laços comunitários em meio à produção da desmobilização ainda embaraça a construção de significados comuns de luta.

\section{Referências}

Acselrad, H.; Mello, C. C. A.; Bezerra, G. das N. O que é justiça ambiental? Rio de Janeiro: Garamond, 2009.

Alavi, H. Las clases campesinas y las lealtades primordiales. Barcelona: Ed. Anagrama, 1976.
Albano, G. P.; Sá, A. J. de. Políticas públicas e globalização da agricultura no Vale do Açu-RN. Revista de Geografia, 25(2), 58-80, 2008.

Almeida, A. W. B. de. Terras de quilombo, terras indígenas, "babaçuais livres", "castanhais do povo", faxinais e 
fundos de pasto: terras tradicionalmente ocupadas. Manaus: PGSCA-UFAM, 2008.

Araújo, A. F. de. Movimento de atingidos por barragens no contexto do desastre do rio doce: formas de mobilização e redes de interações. In: Anais do Encontro Internacional e Nacional de Politica Social. Vitória, 03 de junho de 2019.

Araújo, S. G. de. Assentamentos rurais: trajetória dos trabalhadores assentados e cultura política. Natal: EDUFRN, 2005.

Bourdieu, P. A miséria do mundo. Petrópolis: Vozes, 1997.

Bourdieu, P. Futuro de classe e casualidade do provável. In: Nogueira, M. A.; Catani, A. (Org.). Escritos de Educação. Petrópolis: Vozes, 2007.

Bourdieu, P. O senso prático. Petrópolis: Vozes, 2009.

Brasileiro, F. M. G. Análise da influência dos parques eólicos na modificação das condições climáticas locais em áreas piloto no Ceará e no Rio Grande do Norte. Fortaleza, Dissertação (Mestrado em Geografia) - UFC, 2019.

Cefaï, D. Como nos mobilizamos? A contribuição de uma abordagem pragmatista para a sociologia da ação coletiva. Dilemas - Revista de Estudos de Conflito e Controle Social, 2(4), 11-48, 2009.

Cefaï, D. L'engagement ethnographique. Paris: Ed. de l'Ecole des Hautes Etudes en Sciences Sociales, 2010.

Costa, R. F. da. Ventos que transformam? Um estudo sobre o impacto econômico e social da instalação dos parques eólicos no Rio Grande do Norte/Brasil. Natal, Dissertação (Mestrado em Estudos Urbanos e Regionais) - UFRN, 2015.

Cruz, K. D. B. Os impactos da instalação de parques eólicos nas comunidades urbanas e rurais da Serra e Santana/RN. Natal, Dissertação (Mestrado em Engenharia de Produção) - UFRN, 2016.

Dai, K.; Bergot, A.; Liang, C.; Xiang, W. N.; Huang, Z. Environmental issues associated with wind energy - A review. Renewable Energy, 75, 911-921, 2015.

Felix, S. F. Índice de vulnerabilidade, percepção e impactos socioambientais de parque eólico na comunidade de São Cristóvão, Areia Branca - RN. Mossoró, Dissertação (Mestrado em Ciências Naturais) - UERN, 2018.
Fernandes, B.; Júnior, E. A. Impactos ambientais dos parques eólicos na região da Costa Branca Potiguar. Anais do Encontro de Computação do Oeste Potiguar ECOP/ UFERSA, (1), 2017.

Flyvbjerg, B.; Bruzelius, N.; Rothengatter, W. Megaprojects and risk: An anatomy of ambition. Cambridge: Cambridge University Press, 2003.

Foucault, M. Microfisica do poder. Rio de Janeiro: Paz e Terra, 2014

Giddens, A. A constituição da sociedade. São Paulo: Martins Fontes, 2003.

Improta, R. L. Implicações socioambientais da construção de um parque eólico no município de Rio de Fogo-RN. Natal, Dissertação (Mestrado em Psicologia) - UFRN, 2008.

Lefebvre, H. Prefácio: a produção do espaço. Estudos Avançados, 27(79), 123-132, 2013.

Little, P. E. Territórios sociais e povos tradicionais no Brasil: por uma antropologia da territorialidade. Anuário Antropológico, 28(1), 251-290, 2003.

Little, P. E. Ecologia política como etnografia: um guia teórico e metodológico. Horizontes Antropológicos, 12(25), 85-103, 2006.

Machado, M. R. O processo histórico do desmatamento do Nordeste Brasileiro: impactos ambientais e atividades econômicas. Revista de Geografia, 23(2), 123-134, 2008.

Martínez A. J. O ecologismo dos pobres: conflitos ambientais e linguagens de valoração. São Paulo: Contexto, 2018.

Mbembe, A. Políticas da inimizade. Lisboa: Antígona, 2017.

Mintz, S. W. O poder amargo do açúcar: produtores escravizados, consumidores proletarizados: coletânea de artigos de Sidney W. Mintz. Recife: Editora Universitária UFPE, 2003.

Oliveira, F. R. C.; Rothman, F. D. Arquidiocese de Mariana, Teologia da Libertação e Emergência do Movimento dos Atingidos por Barragens do Alto Rio Doce (MG). Politica \& Sociedade, 7(12), 177-203, 2008.

Palmeira, M. G.; Heredia, B. M. A. Os comícios e a política de facções. Anuário Antropológico, 19(1), 31-94, 1995. 
Pinto, L. I. C.; Martins, F. R.; Pereira, E. B. O mercado brasileiro da energia eólica, impactos sociais e ambientais. Revista Ambiente \& Água, 12(6), 2017.

Pontes, A. G. V.; Gadelha, D.; Freitas, B. M. C.; Rigotto, R. M.; Ferreira, M. J. M. Os perímetros irrigados como estratégia geopolítica para o desenvolvimento do semiárido e suas implicações à saúde, ao trabalho e ao ambiente. Ciência \& Saúde Coletiva, 18, 3213-3222, 2013.

Ramalho, M. F. D. J. L. Considerações sobre o ambiente de rios represados: o caso do rio Piranhas-Açu no Rio Grande do Norte. Sociedade e Território, 21(1-2), 183-196, 2009.

Rozendo, C.; Ferraz, E.; Bastos, F. Que bons ventos as trazem? A investida das usinas eólicas e a reconfiguração dos territórios rurais no Estado do Rio Grande do Norte: desafios e perspectivas. In: Anais do Encontro Anual da ANPOCS, Caxambu, 27 de outubro de 2014.

Saidur, R.; Rahim, N. A.; Islam, M. R.; Solangi, K. H. Environmental impact of wind energy. Renewable and Sustainable Energy Reviews, 15(5), 2423-2430, 2011.

Santos, J. S. A desordem do progresso: o Projeto Baixo-Açu e a expropriação das terras camponesas de trabalho e moradia. In: Anais do $30^{\circ}$ Simpósio Nacional de História da ANPUH. Recife, 15 de julho de 2019.

Scherer-Warren, I.; Reis, M. J. As barragens do Uruguai: dinâmica de um movimento social. Boletim de Ciências Sociais, 41, 25-48, 1986.

Shiva, V. Monoculturas da mente: perspectivas da biodiversidade e da biotecnologia. São Paulo: Gaia, 2003.

Sigaud, L. Efeitos sociais de grandes projetos hidrelétricos: as barragens de Sobradinho e Machadinho. Comunicação $\mathrm{n}^{\circ}$ 9. Programa de Pós-Graduação em Antropologia Social, Museu Nacional, UFRJ, 1986.

Silva, J. D.; Silva, F. Considerações sobre agricultura irrigada no Vale do Açu e os impactos sobre o mundo do trabalho. Revista da ABET, 6(1), 148-170, 2006.
Sousa, F. C. O. A cidade e os homens das salinas. In: Anais do XXIV Simpósio Nacional de História. São Leopoldo, 15 de julho de 2007.

Souza, F. das C. S. Escafandristas do tempo: narrativas de vida e regeneração da memória em São Rafael/RN. Natal, Tese (Doutorado em Educação) - UFRN, 2010a.

Souza, F. das C. S. Memórias, narrativas e trajetórias de vida dos moradores de São Rafael-RN (primeiros apontamentos). Revista Inter-Legere, 6, 2010b.

Souza, J. Max Weber e o "Racismo Científico" da sociologia moderna. Ideias, 5(1), 31-62, 2014.

Tarrow, S. O poder em movimento. Movimentos sociais e confronto político. Petrópolis: Vozes, 2009.

Teixeira, R. O. S. A lama e suas marcas: neoextrativismo e seus efeitos em um contexto de desastre. Revista Perfiles Económicos, 5, 77-103, 2018.

Tribuna do Norte. Lagoa de Piató secou há mais de seis meses. Natal, 2015. Disponível em: $<$ http://www.tribunadonorte.com.br/noticia/lagoa-do-piata-secou-ha-mais-de-dois-meses/305481>. Acesso em: jan. 2020.

Van Der Ploeg, J. D. Sete teses sobre a agricultura camponesa. Revistas Agriculturas: Experiências em Agroecologia, AS-PTA, 6, 17-32, 2009.

Wilkinson, J. Os gigantes da indústria alimentar entre a grande distribuição e os novos clusters a montante. Estudos Sociedade e Agricultura, 18, 147-174, 2002.

Wood, E. O império do capital. São Paulo: Boitempo, 2014.

Zhouri, A.; Laschefski, K. (Eds.). Desenvolvimento e conflitos ambientais. Belo Horizonte: Editora UFMG, 2010.

Zhouri, A.; Valencio, N.; Teixeira, R. O. S.; Zucarelli, M. C.; Laschefski, K.; Santos, Moreira, A. F. O desastre da Samarco e a política das afetações: classificações e ações que produzem o sofrimento social. Ciência e Cultura, 68(3), 36-40, 2016. 